\title{
Riesgo de diseminación por Klebsiella pneumoniae productora de una carbapenemasa del tipo NDM en Lima-Perú
}

\author{
Risk of dissemination of NDM-producing Klebsiella pneumoniae in Lima-Peru
}

\section{Sr Editor:}

Las carbapenemasas del tipo metalo-betalactamasa son enzimas producidas por una secuencia de genes que se encuentra localizada en un plásmido. Pertenecen a la clase B según la clasificación de Ambler. Confieren resistencia a todos los betalactámicos, incluyendo a los carbapenemes con excepción del aztreonam (1).

En el 2008 en Suecia, por primera vez en el mundo, se detectó una carbapenemasa del tipo NDM (New Delhi metallo- $\beta$-lactamase) producida por una cepa de Klebsiella pneumoniae, en un paciente que realizaba viajes continuos a la India (2). Desde entonces las cepas productoras de carbapenemasas del tipo NDM se encuentran en expansión a nivel mundial (3).

En Perú, en junio del 2017, en el Hospital Dos de Mayo de Lima se reportó nueve aislamientos de cepas de Klebsiella pneumoniae productora de una carbapenemasa del tipo NDM, confirmada molecularmente por el Instituto Nacional de Salud (INS) (4). En el 2018, el INS notificó la presencia de genes de resistencia del tipo NDM en 56 enterobacterias, aisladas en diversos centros hospitalarios de Lima y provincias desde el 2013 al 2017 (5).

Se presenta el caso de una mujer de 20 años atendida en el Instituto Nacional de Rehabilitación a quien se le solicitó cultivo de orina en la evaluación inicial. La paciente no presentaba cuadro clínico de infección urinaria y no tenía catéter vesical. En el referido urocultivo, se identificó una cepa de Klebsiella pneumoniae productora de una $\beta$-lactamasa de espectro extendido (por método francés y americano) y una metalo- $\beta$-lactamasa (método de aproximación de meropenem e imipenem con EDTA) como mecanismos de resistencia, y la susceptibilidad antimicrobiana informó como alternativa de tratamiento a amikacina y colistina. El INS confirmó por métodos moleculares, la presencia del genotipo de resistencia del tipo NDM.

La paciente refirió haber estado hospitalizada 35 días en el Hospital Dos de Mayo y portar un catéter urinario permanente mientras estuvo hospitalizada. Por ello, es muy probable que haya adquirido esta cepa multirresistente en su hospitalización previa.

La identificación oportuna del mecanismo de resistencia impidió que la paciente se hospitalice en nuestro Instituto, lo cual evitó un probable brote. Sería pertinente realizar los análisis moleculares para determinar si la cepa aislada en nuestro laboratorio está relacionada con alguna de las nueve cepas aisladas en el Hospital Nacional Dos de Mayo. Debido al aumento de reportes a nivel mundial y actualmente de reportes en el Perú, se deberían extremar las medidas preventivas, como la detección oportuna de mecanismos que confieran resistencia a carbapenémicos y la vigilancia epidemiológica tanto de pacientes infectados como colonizados.

Matias Penagos-Avila ${ }^{1, a}$

\section{Correspondencia:}

Matias Penagos-Avila

Dirección: Av. Prol. Defensores del Morro, cuadra 2, Distrito de Chorrillos 15057 - Lima, Perú

Correo electrónico: matiaspenagos2367@gmail.com

Área de Microbiología, Instituto Nacional de Rehabilitación “Dra. Adriana Rebaza Flores”. Lima, Perú.

Biólogo con mención en microbiología y parasitología. 


\section{REFERENCIAS BIBLIOGRÁFICAS}

1. Bush K, Jacoby GA, Medeiros AA. A functional classification scheme for beta-lactamases and its correlation with molecular structure. Antimicrob Agents Chemother [Internet]. 1995 [citado 16 de noviembre del 2018];39(6):1211-33. Disponible en: https://aac.asm.org/content/39/6/1211

2. Yong D, Toleman MA, Giske CG, Cho HS, Sundman K, Lee K, et al. Characterization of a New Metallo- $\beta$-Lactamase Gene, blaNDM-1, and a Novel Erythromycin Esterase Gene Carried on a Unique Genetic Structure in Klebsiella pneumoniae Sequence Type 14 from India. Antimicrob Agents Chemother [Internet]. 2009 [citado 16 de noviembre del 2018];53(12):5046-54. Disponible en: https://aac.asm.org/content/53/12/ 5046

3. Nordmann P, Naas T, Poirel L. Global spread of Carbapenemase-producing Enterobacteriaceae. Emerg Infect Dis [Internet]. 2011 [citado 16 de noviembre del 2018];17(10):1791-8. Disponible en: https://wwwnc.cdc.gov/eid/article/17/10/110655_article
4. Resurrección-Delgado C, Montenegro-Idrogo JJ, Chiappe-Gonzalez A, Vargas-Gonzales R, CuchoEspinoza C, Mamani-Condori DH, et al. Klebsiella pneumoniae nueva Delhi metalo-betalactamasa en el Hospital Nacional Dos de Mayo: Lima, Perú. Rev Peru Med Exp Salud Publica [Internet]. 2017 [citado 16 de noviembre del 2018];34(2):261-7. Disponible en: https://rpmesp.ins.gob.pe/index. php/rpmesp/article/view/2615

5. Sacsaquispe-Contreras R, Bailón-Calderón $H$. Identificación de genes de resistencia a carbapenémicos en enterobacterias de hospitales de Perú, 2013-2017. Rev Peru Med Exp Salud Publica [Internet]. 2018 [citado 16 de noviembre del 2018];35(2):259-64. Disponible en: https:// rpmesp.ins.gob.pe/index.php/rpmesp/article/ view/3829

Recibido: 30/07/2019 